\title{
AUTOMATIZAÇÃO DO SISTEMA DE ABASTECIMENTO DE ÁGUA DE UM INFILTRÔMETRO DE ANÉIS CONCÊNTRICOS PARA UTILIZAÇÃO EM SOLOS COM ALTA CAPACIDADE DE INFILTRAÇÃO
}

\section{AUTOMATION OF THE WATER SUPPLY SYSTEM OF A DOUBLE RING INFILTROMETER FOR USE IN SOILS WITH HIGH INFILTRATION CAPACITY}

Juremá Ariana Oliveira Silva

Graduanda em Engenharia Sanitária e Ambiental, Universidade Federal do Oeste da Bahia. (silva.ariana.j@gmail.com)

Jhames Passos Sateles

Graduando em Engenharia Civil, Universidade Federal do Oeste da Bahia. (ihamesjps2009@hotmail.com)

Anderson Galindo Teixeira

Graduando em Engenharia Civil, Universidade Federal do Oeste da Bahia. (andersonteixeira @hotmail.com)

Inaldo Nóbrega da Cunha Filho

Graduando em Engenharia Civil, Universidade Federal do Oeste da Bahia. (inaldonobrega@gmail.com)

Luís Gustavo Henriques do Amaral

Doutor em Engenharia Agrícola, Universidade Federal de Viçosa. Universidade Federal do Oeste da Bahia. (luis.gha@ufob.edu.br)

\section{Resumo}

Apesar da facilidade de manejo do infiltrômetro de anéis concêntricos, o seu abastecimento de água exige um trabalho considerável para medição da velocidade de infiltração da água no solo. Para evitar um rebaixamento excessivo da lâmina d'água, é necessário repor constantemente a água no interior dos anéis. Ademais, o acesso à régua linimétrica é desconfortável e pode acarretar erros de medição. Objetivou-se com este trabalho desenvolver um protótipo de um infiltrômetro de anéis concêntricos com funcionamento automatizado, que permita a manutenção de uma carga hidráulica constante no interior dos anéis, quando utilizado em solos com alta capacidade de infiltração. Com base em testes preliminares, foram determinados os parâmetros do projeto do sistema de alimentação de água nos anéis. Por meio da confecção de reservatórios para abastecimento dos anéis e da sua associação com válvulas de boia, manteve-se constante o nível de água no interior dos anéis, mesmo para altas taxas de infiltração, acima de $500 \mathrm{~mm} \mathrm{~h}^{-1}$.

Palavras-chave: infiltração da água no solo; válvula de boia; lâmina d'água

\section{Abstract}

Despite the simplicity and ease of use of the double ring infiltrometer, its water supply requires substantial work to measure the infiltration rate of water into the soil. To avoid excessive water retraction, it is necessary to constantly replace the water inside the rings. In addition, access to the linimetric ruler is uncomfortable and can lead to measurement errors. The objective of this work was to develop a prototype of a double ring infiltrometer with an automated operation that allows the maintenance of a constant hydraulic head inside the rings when used in soils with high infiltration capacity. Based on preliminary tests, the design parameters of the water supply system were determined. The level of water inside the rings was maintained constant, even at high infiltration rates above $500 \mathrm{~mm} \mathrm{~h}^{-1}$, by means of the preparation of reservoirs to supply the rings and their association with float valves.

Keywords: infiltration of water into the soil; float valve; water blade 


\section{INTRODUÇÃO E FUNDAMENTAÇÃO TEÓRICA}

Diversos métodos podem ser utilizados para a determinação da velocidade de infiltração da água no solo, dentre os quais se destacam os simuladores de chuva e os infiltrômetros de anéis concêntricos (IAC). Os IAC são mais utilizados devido à sua facilidade de manejo e ao baixo custo de aquisição, quando comparados aos simuladores de chuva (COELHO et al., 2000; SIMÕES et al., 2005). Além disso, os IAC podem ser utilizados em locais em que o acesso à água é restrito, uma vez que a quantidade utilizada nos ensaios é relativamente pequena, quando comparada à necessária para a realização de um ensaio com simulador de chuvas.

No IAC, dois anéis metálicos de diâmetros diferentes são introduzidos no solo por percussão, de forma concêntrica. Introduz-se água no interior dos dois anéis, mantendo-se uma lâmina de água sobre a superfície do solo. A quantidade de água introduzida no interior do anel menor é monitorada em intervalos préestabelecidos, até que a lâmina infiltrada se torne constante.

Apesar da facilidade de manejo e da simplicidade de utilização, o IAC exige uma carga de trabalho considerável durante sua operação, visto que é necessário repor constantemente a água no interior dos anéis para evitar um rebaixamento excessivo da lâmina d'água, o que pode comprometer os resultados do teste. Além disso, é necessário o monitoramento da lâmina infiltrada no interior do anel menor em intervalos de tempo pequenos, o que geralmente implica na dedicação de um operador apenas para essa função. Como esse anel é cravado no solo, o acesso à régua para realização das leituras é desconfortável, podendo acarretar erros de medição. Para que as atividades de reposição e monitoramento sejam realizadas de maneira satisfatória, geralmente é necessária a dedicação de dois operadores durante a realização de um único ensaio que, em certos casos, pode durar algumas horas.

Uma alternativa para facilitar a operação do IAC é a automatização do seu funcionamento. Moreira et al. (2000) apresentaram um protótipo de infiltrômetro de carga constante construído com materiais de baixo custo, baseando-se no infiltrômetro de pressão positiva projetado por Perroux e White (1988). Esse infiltrômetro também permite a manutenção de uma carga hidráulica constante ao longo do ensaio, sendo necessário apenas o monitoramento da variação da lâmina d'água. Porém, é inadequado para ensaios em solos que possuam capacidade de infiltração superior a $90 \mathrm{~mm} \mathrm{~h}^{-1}$, como pode ocorrer em solos arenosos e franco-arenosos, pois a quantidade de água necessária superaria a capacidade de alimentação do equipamento.

Por outro lado, Bono et al. (2012) adaptaram uma estrutura de madeira e um sistema de boias para regular a entrada de água nos anéis e manter a mesma carga hidráulica em seu interior, conseguindo medir taxas de infiltração da ordem de $1000 \mathrm{~mm} \mathrm{~h}^{-1}$. No entanto, nesse trabalho, não são especificados os critérios de projeto e os detalhes de operação do equipamento, principalmente em relação à forma de reposição de água no reservatório de alimentação do anel interno, de maneira a manter a continuidade dos testes em solos com alta capacidade de infiltração.

Lima Filho e Costa (2015) desenvolveram um equipamento automático para determinação da capacidade de infiltração da água no solo que, além de um sistema de boias adaptadas aos anéis, possibilitava 0 registro automático da variação da altura da lâmina d'água no anel interno. Para tanto, foram adaptados à parte superior do reservatório de alimentação do anel interno um microcontrolador Arduino com um sensor ultrassônico. Nesse trabalho, também não são apresentados os detalhes referentes ao projeto e à operação do equipamento, principalmente no que tange à capacidade do reservatório de alimentação de água.

$\mathrm{Na}$ região Oeste da Bahia, predominam os Latossolos Vermelho-Amarelos, que apresentam altas taxas de infiltração estáveis. A medição da capacidade de infiltração desses solos é dificultada pela necessidade de se utilizar grandes volumes de água para a realização dos ensaios, o que implica em efetuar inúmeras operações de reabastecimento dos anéis quando o IAC não é automatizado. Por outro lado, o uso de IACs automatizados requer 0 dimensionamento adequado dos reservatórios de abastecimento dos anéis, de modo que não falte água para a realização dos testes.

Assim, o objetivo deste trabalho foi desenvolver um protótipo de um infiltrômetro de anéis concêntricos com funcionamento automatizado, que permita a manutenção de uma carga hidráulica constante no interior dos anéis, quando utilizado em solos com alta capacidade de infiltração. 


\section{METODOLOGIA}

\section{Testes de infiltração preliminares}

O uso do IAC em solos com alta capacidade de infiltração exige um mecanismo de alimentação de água com vazão suficiente para suprir a demanda do ensaio. Para determinar a vazão mínima necessária para o sistema de alimentação, bem como os volumes mínimos dos reservatórios de alimentação dos anéis interno e externo, foram realizados testes preliminares em uma área de cerrado nativo pertencente ao campus Reitor Edgard Santos da Universidade Federal do Oeste da Bahia, no município de Barreiras, BA. Durante os testes preliminares, encontraram-se valores da taxa de infiltração estável (TIE) da ordem de $500 \mathrm{~mm} \mathrm{~h}^{-1}$, sendo assim determinado o consumo total de água nos anéis interno e externo, bem como a vazão máxima necessária para a manutenção do processo de infiltração. A partir destes dados, foram calculados os volumes dos reservatórios para alimentação dos anéis e obtidas as especificações para as válvulas de boia.

\section{Montagem do sistema de alimentação}

O mecanismo de alimentação foi composto, basicamente, por dois reservatórios conectados a duas válvulas de boia para o controle da vazão nos anéis interno e externo. O dimensionamento dos reservatórios e a especificação das válvulas de boia foram realizados com base nos ensaios preliminares.

O reservatório de alimentação do anel interno foi construído a partir de um tubo de PVC de diâmetro comercial de $200 \mathrm{~mm}$ (192,8 mm de diâmetro interno). Utilizou-se um pedaço de tubo com $1,2 \mathrm{~m}$ de comprimento, dos quais $0,9 \mathrm{~m}$ foi destinado à reserva de água e $0,3 \mathrm{~m}$ utilizado para acomodação das conexões e para conferir uma carga hidráulica mínima necessária ao funcionamento da válvula de boia (Figura 1).

Figura 1. Esquema do reservatório de alimentação do anel interno

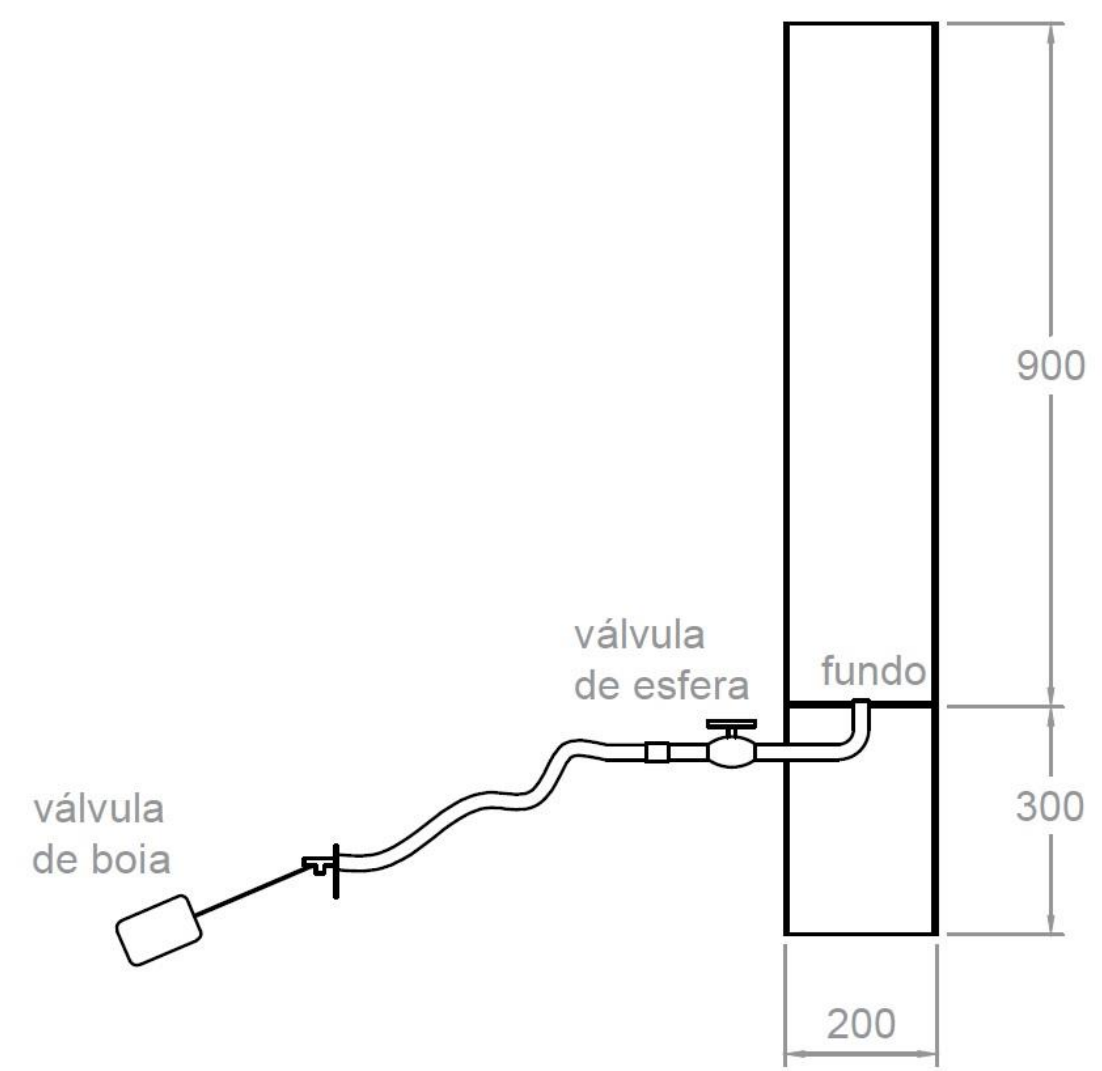

Fonte: Elaborada pelos autores.

O reservatório de alimentação do anel interno foi dimensionado para armazenar um volume de aproximadamente $26 \mathrm{~L}$, suficiente para a realização de um teste de infiltração completo.
Este volume de água disponibiliza uma lâmina equivalente a cerca de $550 \mathrm{~mm}$ no anel interno no infiltrômetro. Para o reservatório de alimentação do anel externo, escolheu-se um galão com 
capacidade de $100 \mathrm{~L}$ de água, com base no consumo de água durante os testes de infiltração preliminares.

A água foi conduzida ao interior dos anéis concêntricos por meio de mangueiras conectadas aos reservatórios. Nas extremidades das mangueiras, foram conectadas válvulas de boia de 12", fabricadas para utilização em bebedouros. A conexão das mangueiras às válvulas de boia foi realizada com um sistema de engate rápido, de modo a facilitar a montagem no campo. As válvulas de boia foram fixadas diretamente sobre os anéis, por meio de um sistema de encaixe, e serviram para a manutenção de uma carga hidráulica constante sobre a superfície do solo (Figura 2). No interior das paredes dos anéis, colaram-se réguas milimetradas para o monitoramento das lâminas d'água nos anéis interno e externo, possibilitando a identificação de possíveis variações.

\section{Figura 2. Válvulas de boia fixadas aos anéis e conectadas às mangueiras para manutenção de carga hidráulica constante sobre a superfície do solo}

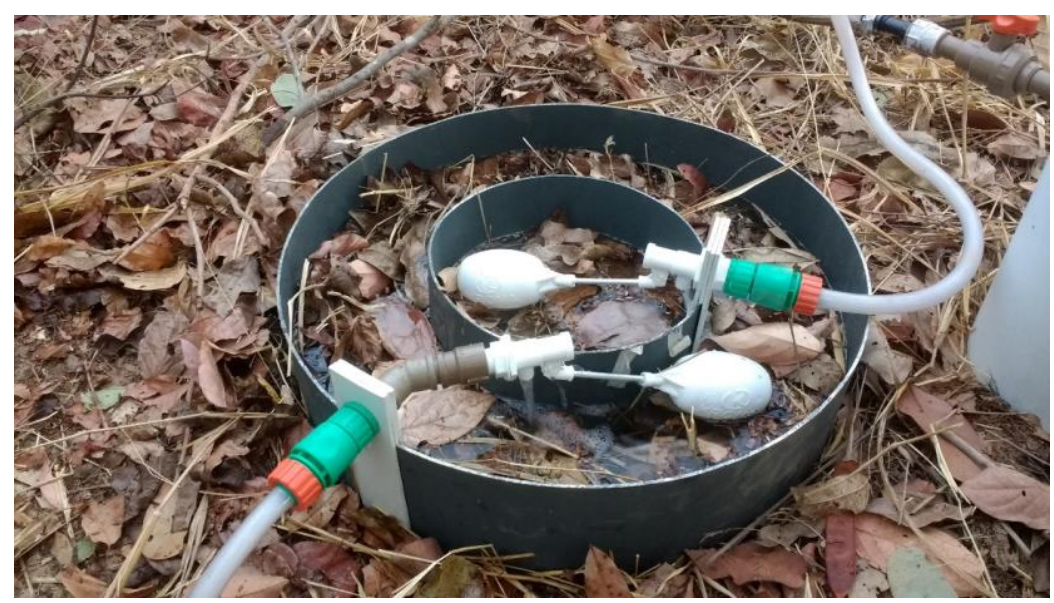

Fonte: Os autores.

Para garantir a manutenção de uma vazão mínima ao anel interno, foi necessário elevar o fundo do reservatório de alimentação desse anel, de modo que fosse mantida uma carga hidráulica mínima para o funcionamento da válvula de boia. Assim, o fundo do reservatório de alimentação do anel interno foi construído com um disco de PVC de diâmetro igual a $192 \mathrm{~mm}$, confeccionado a partir de placas de PVC de $4 \mathrm{~mm}$ de espessura. Esse disco foi fixado sobre uma peça de apoio de PVC colada na parede interna do tubo, de modo a garantir uma boa fixação (Figura 3). Após ser encaixado no tubo, o disco foi colado com adesivo próprio para PVC e vedado com cola de silicone em sua parte superior.

No fundo do reservatório, fez-se um orifício para fixação de uma curva de PVC de $90^{\circ}$, de 20 $\mathrm{mm}$ de diâmetro. A essa curva foi conectada uma luva, cuja ponta com rosca foi posicionada na parede do reservatório (Figura 4).
A parede do reservatório foi perfurada, expondo a luva e possibilitando a sua conexão com o sistema de condução da água até a válvula de boia. A luva foi posicionada rente à parede do reservatório, para evitar danos ao equipamento durante $o$ transporte (Figura 5).

A conexão do reservatório de alimentação ao interior do anel interno foi realizada por meio de uma mangueira. Numa extremidade da mangueira, acoplou-se uma válvula de esfera e um adaptador, o que permitiu a conexão da mangueira com $\mathrm{o}$ reservatório. $\mathrm{Na}$ outra extremidade, foi acoplado um sistema de engate rápido, o qual possibilitou a conexão com a válvula de boia.

$\mathrm{Na}$ parede externa do reservatório, foi acoplada uma régua linimétrica com resolução de $1 \mathrm{~mm}$, de modo que a infiltração acumulada pudesse ser monitorada visualmente, por meio da leitura subposta a uma mangueira (Figura 6). 
Figura 3. Modo de fixação do fundo do reservatório De alimentação do anel interno

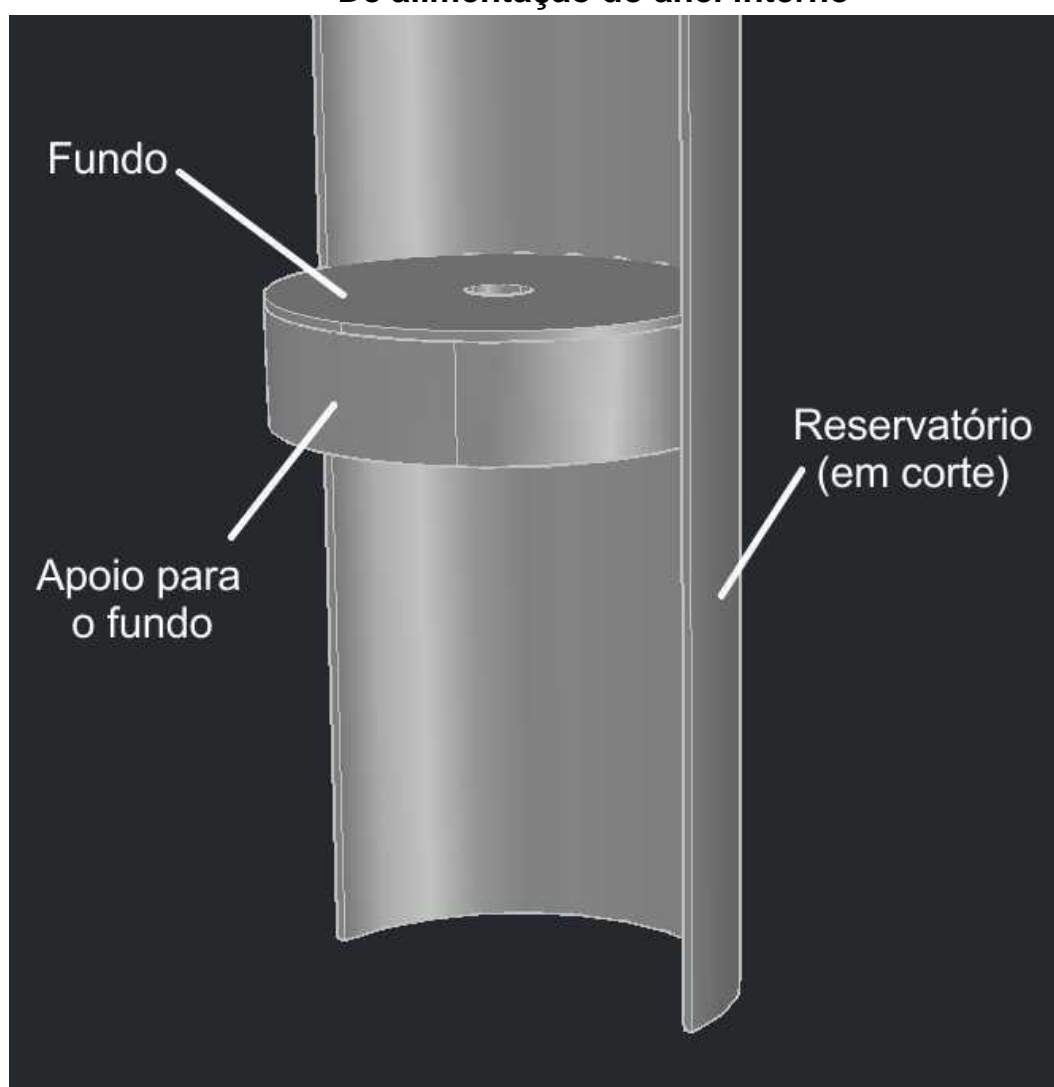

Fonte: Elaborada pelos autores.

Figura 4. Montagem da curva de $90^{\circ}$ no fundo do reservatório de alimentação

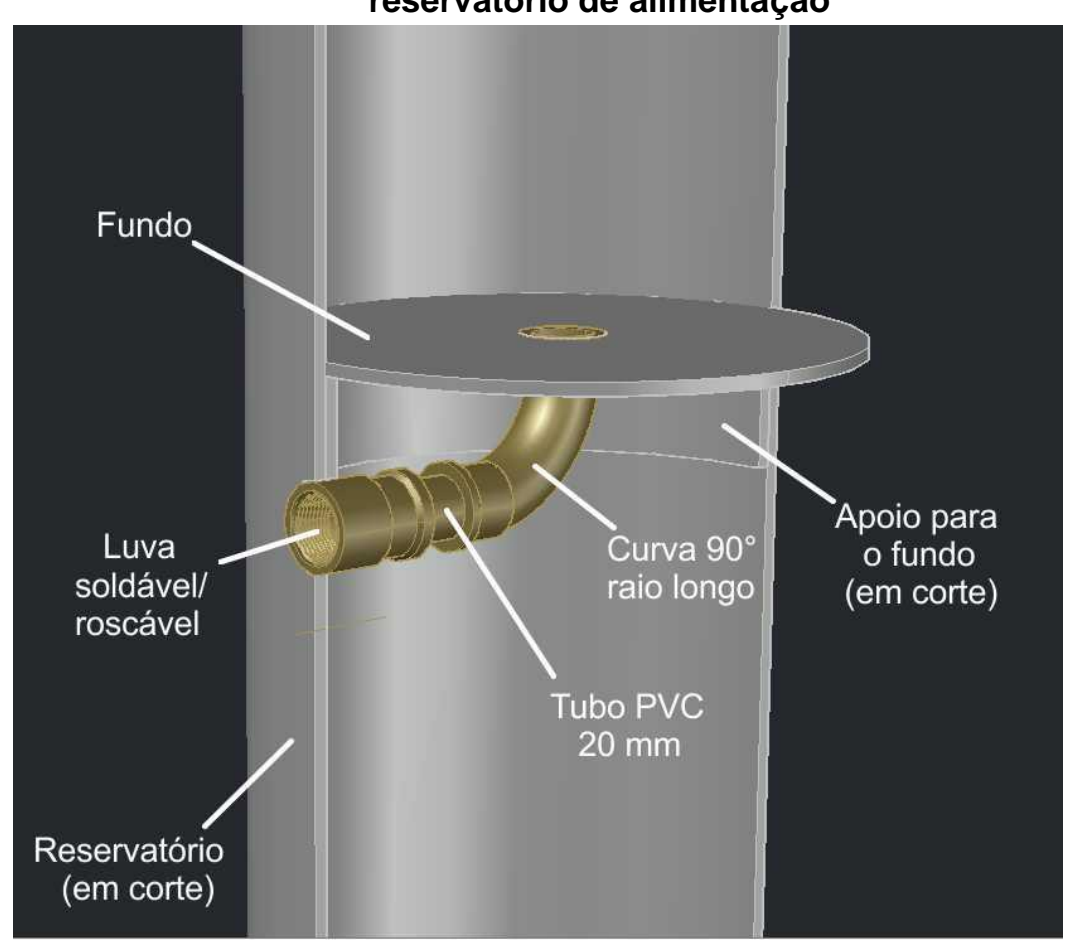

Fonte: Elaborada pelos autores. 
Figura 5. Posicionamento da luva com rosca na parede do reservatório de alimentação

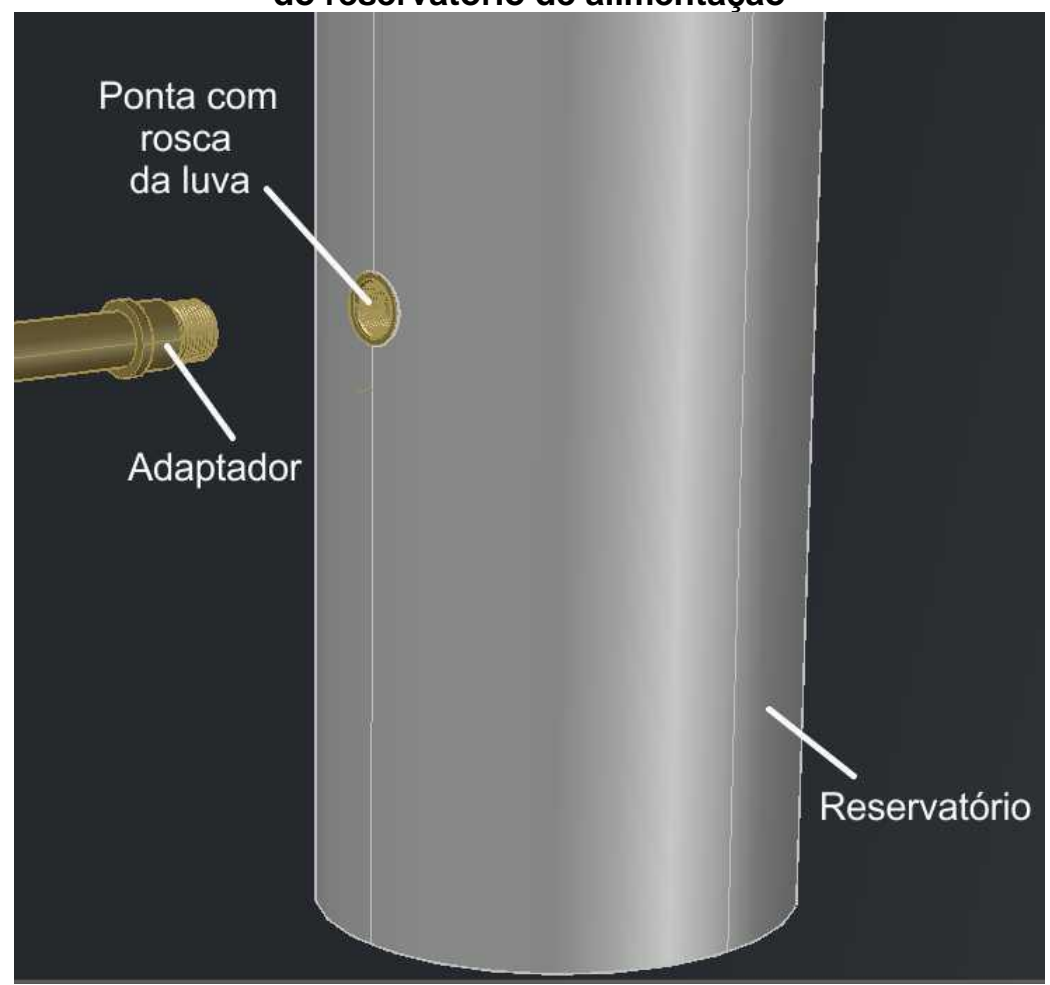

Fonte: Elaborada pelos autores.

Figura 6. Régua linimétrica acoplada ao reservatório de alimentação do anel interno

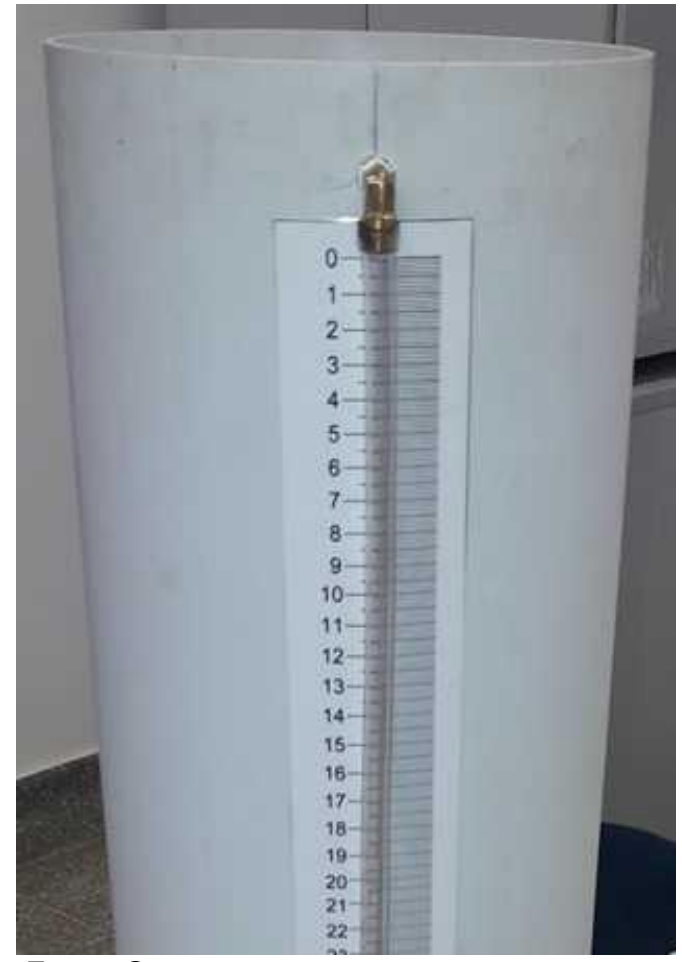

Fonte: Os autores.

Para obtenção da infiltração acumulada, foi necessária a conversão da leitura na régua linimétrica, considerando a diferença entre os diâmetros do reservatório e do anel interno. Essa conversão foi realizada por meio da seguinte equação: 


$$
\Delta h=\frac{A_{\text {res }}}{A_{\text {inf }}} \Delta H
$$

em que:

$\Delta$ h é a variação da altura da lâmina d'água no anel interno (mm);

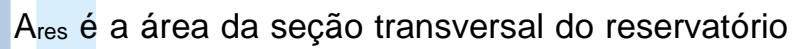
$\left(\mathrm{cm}^{2}\right)$;

Ainf é a área da seção transversal do anel interno $\left(\mathrm{cm}^{2}\right) ; \mathrm{e}$

$\Delta \mathrm{H}$ é a variação da altura da lâmina d'água no reservatório $(\mathrm{mm})$.

\section{Verificação do funcionamento do sistema em campo}

Após a construção do sistema de alimentação, foram realizados testes de campo para verificar a eficiência do sistema. Para tanto, buscou-se medir a capacidade de infiltração do solo em áreas sob diferentes usos. Efetuaram-se quatro testes de infiltração, sendo um em área de cerrado nativo e três em áreas cultivadas com culturas anuais, localizadas nos municípios de São Desidério, Correntina e Jaborandi, na região
Oeste do estado da Bahia, em solos classificados como Latossolos Vermelho-Amarelos.

Durante os testes, buscou-se acompanhar a altura da lâmina d'água nos anéis interno e externo, de modo a verificar possíveis oscilações e analisar se a água disponível nos reservatórios seria suficiente para a realização de um teste completo sem necessidade de reposição.

\section{RESULTADOS, ANÁLISE E DISCUSSÃO}

Com o infiltrômetro em funcionamento, verificou-se que a automatização do sistema de abastecimento de água possibilitou, de fato, a manutenção de alturas de lâmina d'água constantes no interior dos anéis. Contudo, observou-se que, para níveis dos reservatórios de alimentação muito baixos, a vazão descarregada pelas boias não foi suficiente para manter constantes as lâminas d'água no interior dos anéis. Em função disso, foi necessária a elevação dos reservatórios por meio de um suporte de madeira de aproximadamente $0,4 \mathrm{~m}$ de altura (Figura 7).

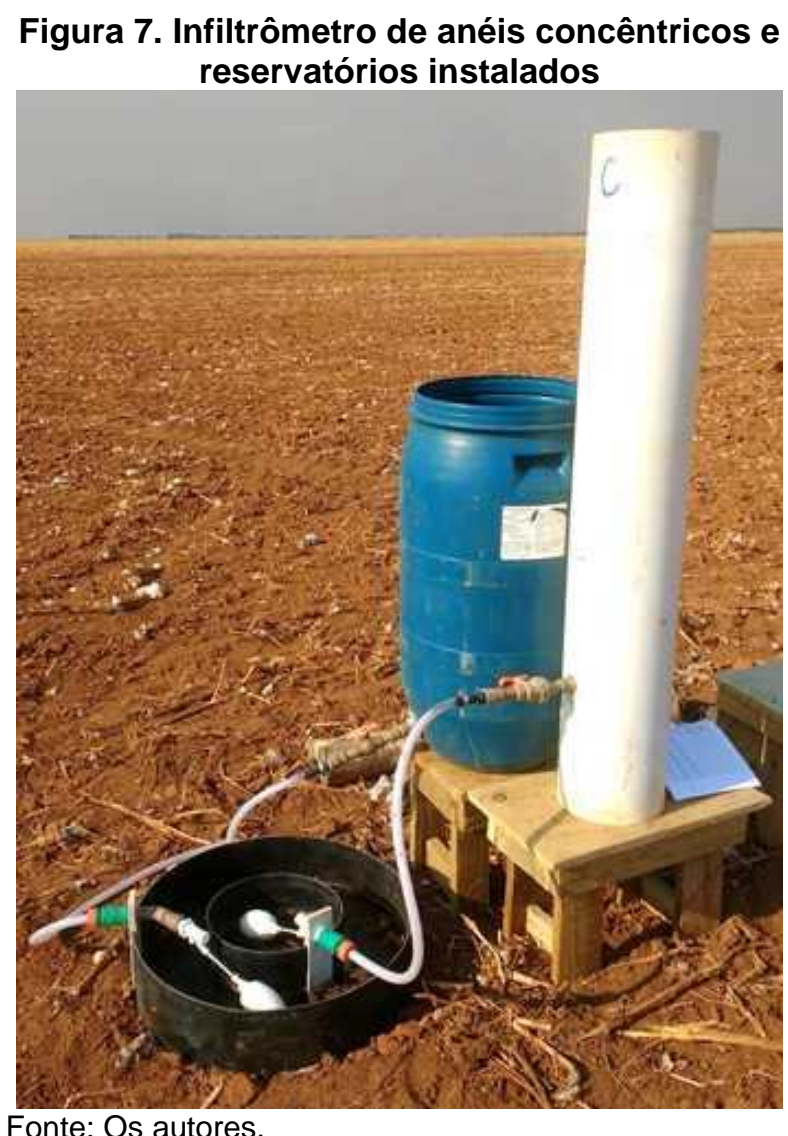

Observando-se as variações da taxa de infiltração e da infiltração acumulada durante os testes, ilustradas nas figuras 8 a 11, verificou-se que os dados de infiltração acumulada 
apresentaram crescimento linear à medida em que as taxas de infiltração tenderam para valores constantes, correspondentes à taxa de infiltração estável do solo no local do ensaio. Este comportamento condiz com a previsão teórica, demonstrando que o processo de coleta de dados foi satisfatório.

Figura 8. Taxa de infiltração e infiltração acumulada medidas em área de plantio convencional, no município de Correntina, BA

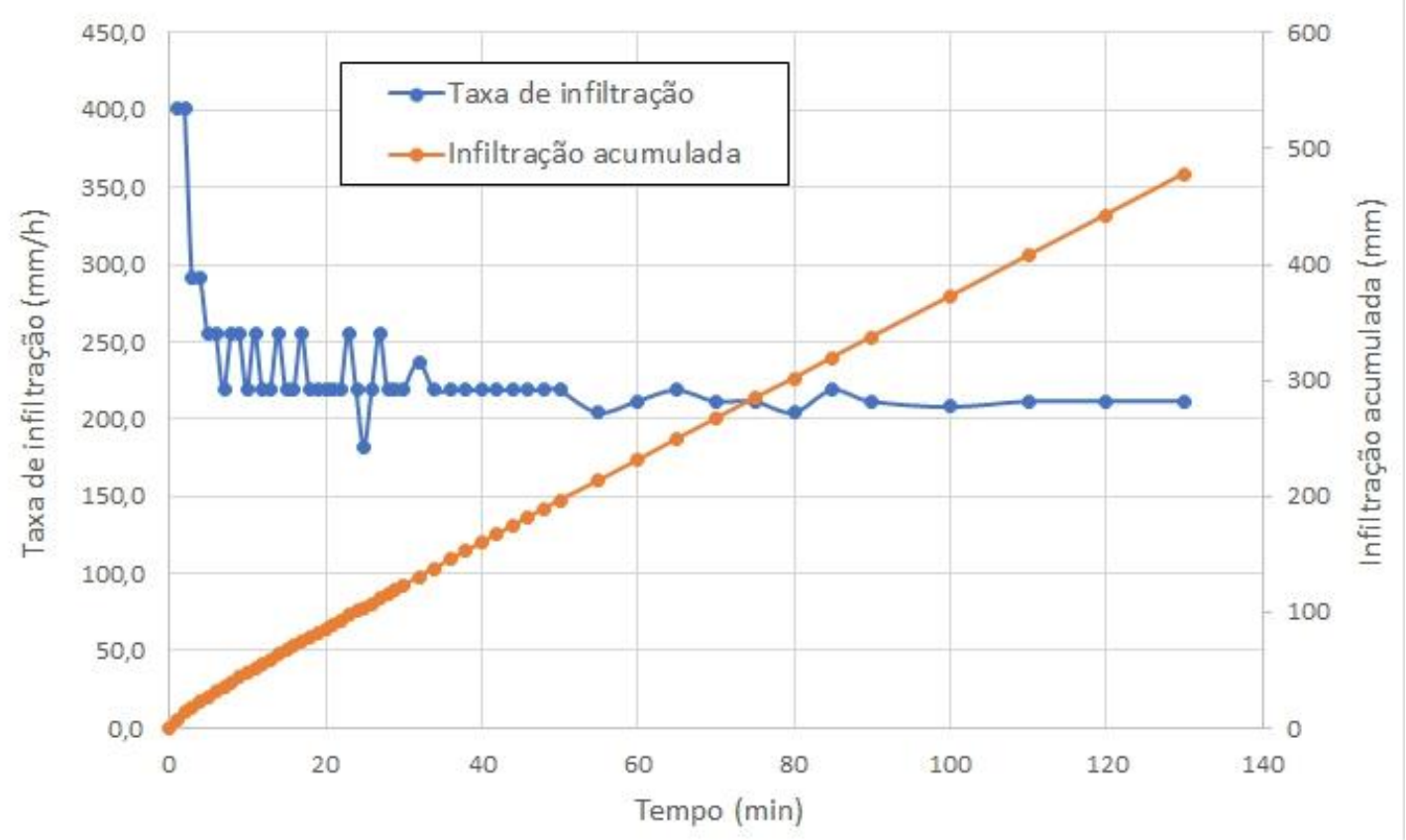

Fonte: Elaborada pelos autores.

Figura 9. Taxa de infiltração e infiltração acumulada medidas em área de plantio direto, no município de Correntina, BA

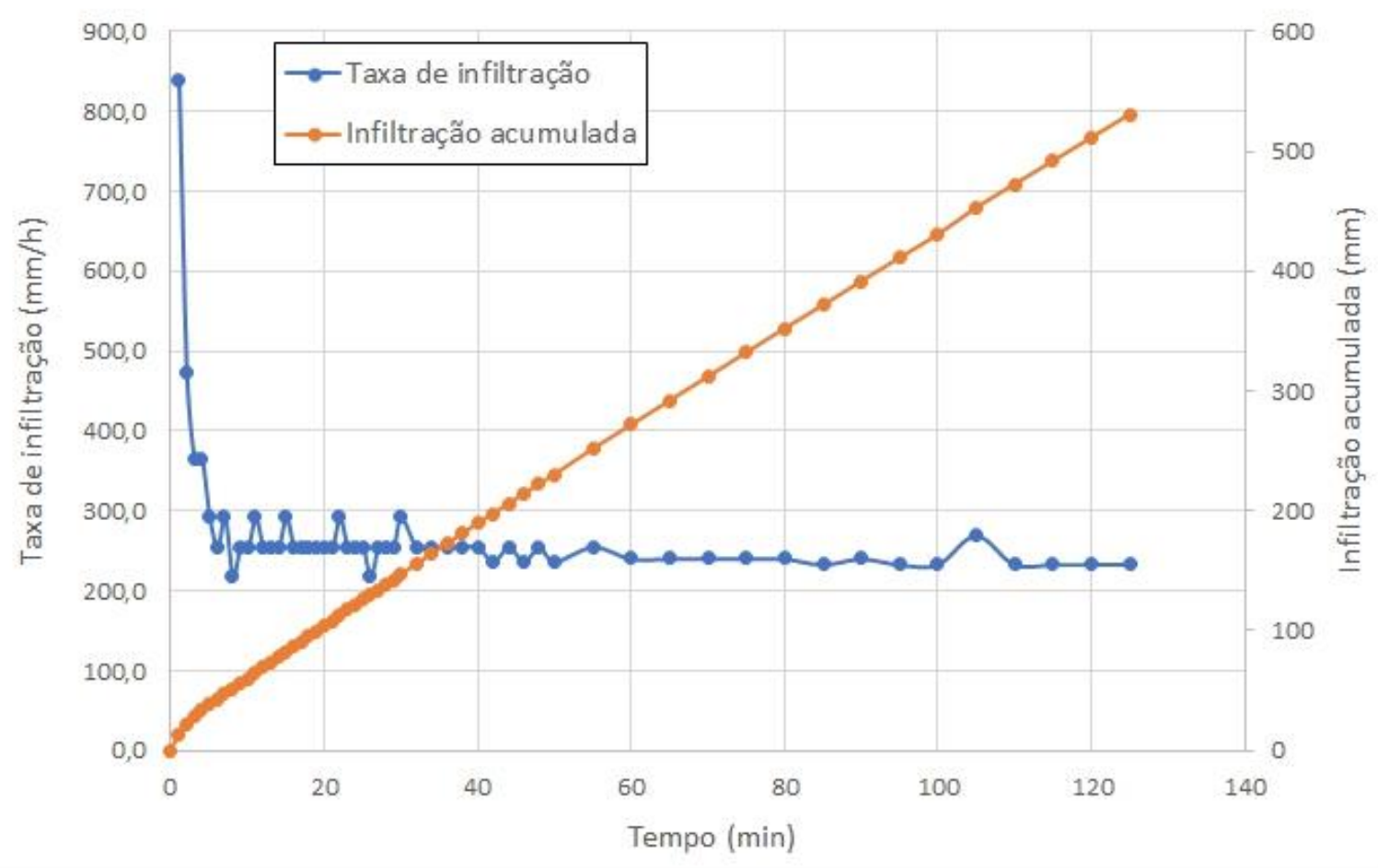

Fonte: Elaborada pelos autores. 
Figura 10. Taxa de infiltração e infiltração acumulada medidas em área de cerrado, no município de Jaborandi, BA

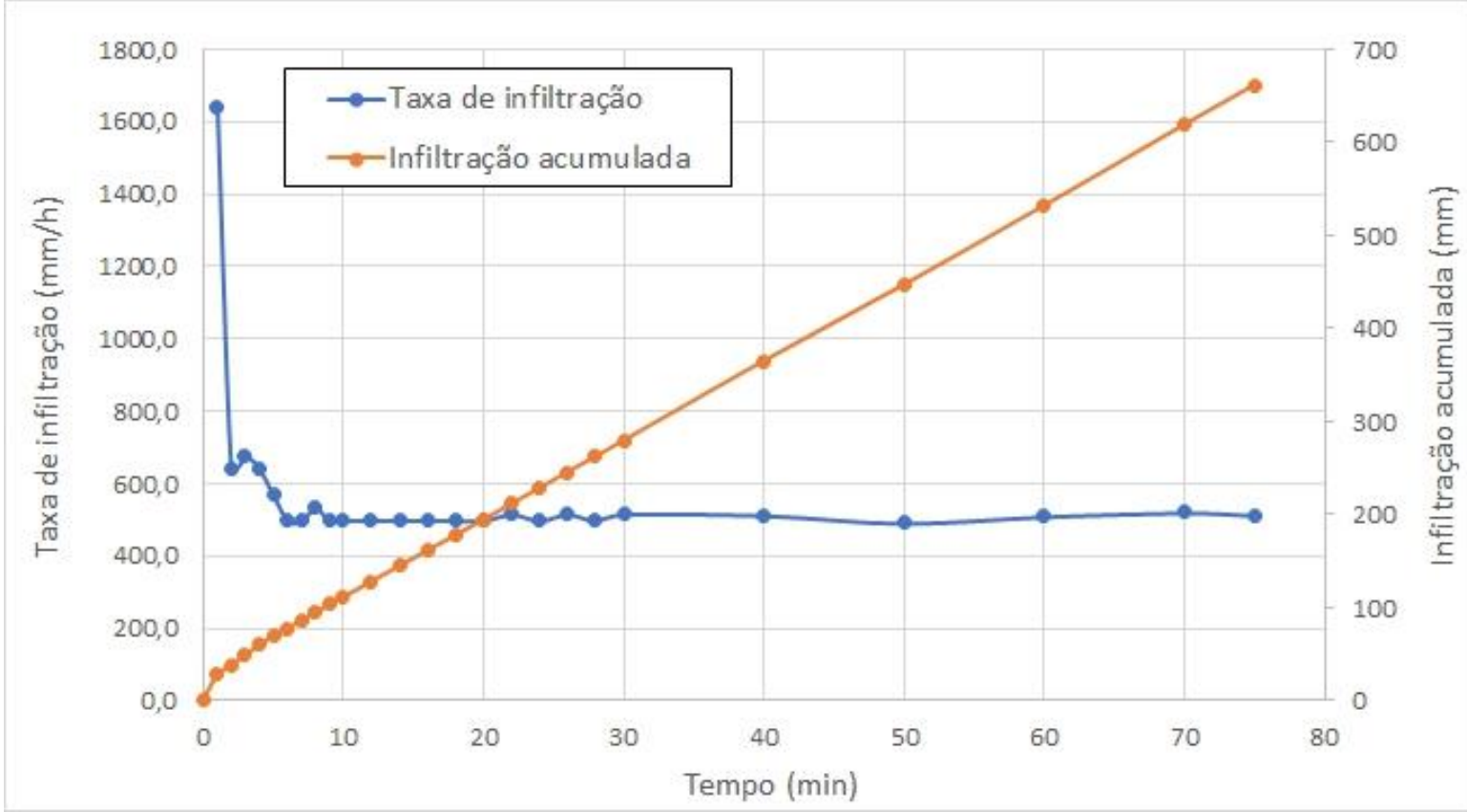

Fonte: Elaborada pelos autores.

Figura 11. Taxa de infiltração e infiltração acumulada medidas em área de plantio convencional, no município de São Desidério, BA

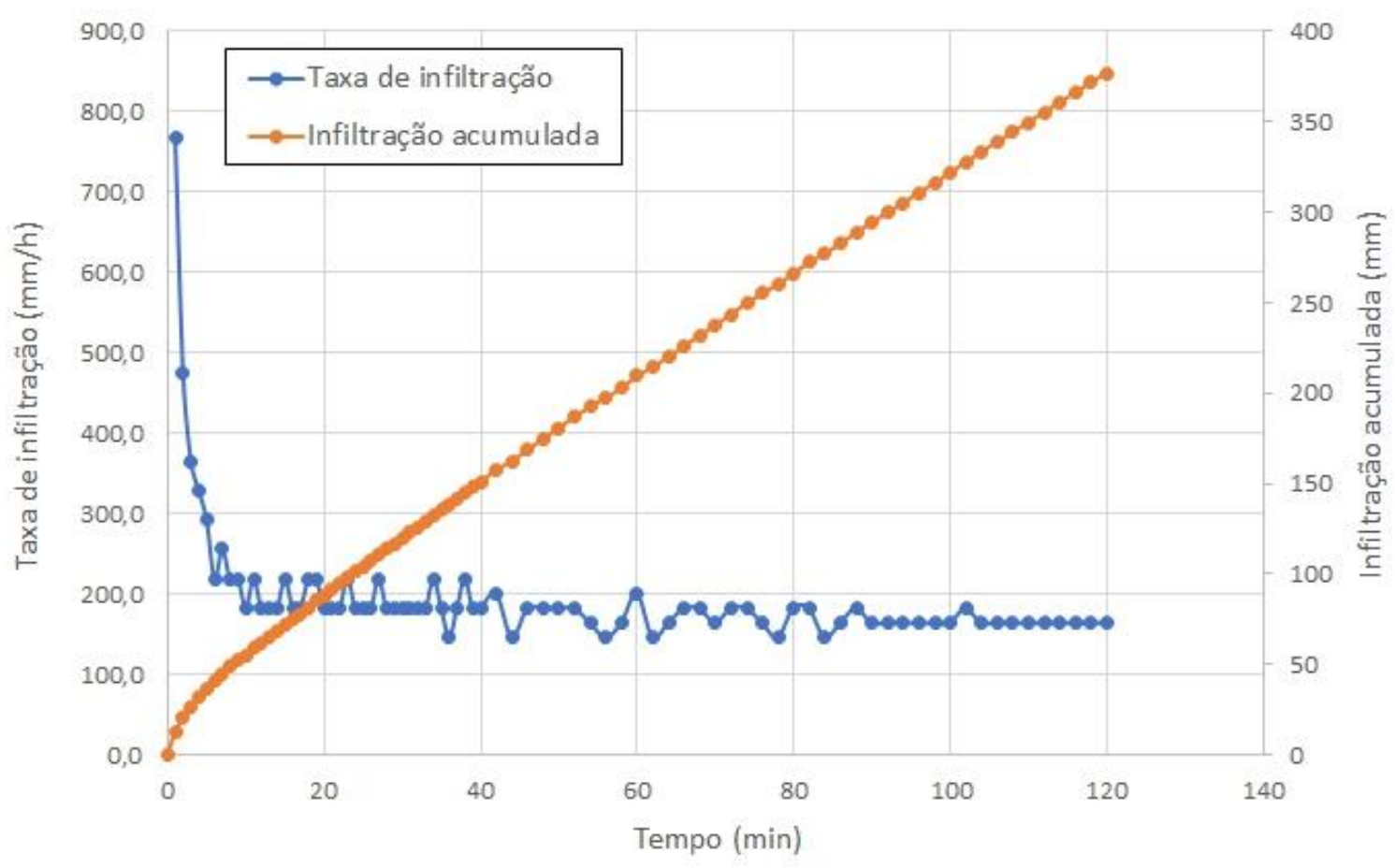

Fonte: Elaborada pelos autores

Apesar de os volumes dos reservatórios terem sido determinados com base em testes preliminares, foi necessária a reposição da água nos reservatórios de alimentação em alguns ensaios de campo, devido às altas taxas de infiltração observadas, que ultrapassaram os 500 $\mathrm{mm} \mathrm{h}-1$, havendo a extrapolação dos valores estimados para as capacidades dos reservatórios. A reposição da água no reservatório de alimentação do anel interno foi realizada por meio de um recipiente de volume conhecido, de modo que a lâmina reposta correspondesse a um valor 
fixo, permitindo a continuidade do teste. Utilizouse um recipiente com aproximadamente 5 L, suficiente para a reposição de $180 \mathrm{~mm}$ no reservatório de alimentação do anel interno.

Em relação à operação do sistema, verificouse a possibilidade de condução dos ensaios com apenas um operador para realizar a leitura na régua linimétrica, o acompanhamento dos níveis de água nos anéis e a reposição de água nos reservatórios, quando necessária. Por outro lado, a posição do reservatório de alimentação do anel interno permitiu que as leituras na régua linimétrica fossem realizadas com maior conforto para o operador. Além disso, a utilização de um reservatório com área da seção transversal menor que a área da seção transversal do anel interno possibilitou que a resolução das medidas da lâmina d'água infiltrada fosse inferior a $1 \mathrm{~mm}$, contribuindo para melhorar a precisão do equipamento.

Salienta-se que o bom funcionamento do sistema depende do funcionamento das válvulas de boia, sendo recomendado o acompanhamento dos níveis de água nos anéis, de modo a identificar qualquer tendência de redução ou interrupção na vazão fornecida pelas válvulas.

O funcionamento satisfatório das válvulas de boia, somado ao comportamento da taxa de infiltração e da infiltração acumulada dentro do esperado demonstraram a eficiência do uso do sistema automatizado de alimentação de água dos anéis do IAC.

\section{CONCLUSÃO}

A partir dos resultados obtidos, conclui-se que o sistema automatizado de abastecimento do infiltrômetro de anéis concêntricos é adequado para utilização em solos com alta capacidade de infiltração, possibilitando a manutenção do nível de água constante nos anéis interno e externo, facilitando a operação e a aquisição de dados e permitindo a reposição de água nos reservatórios, quando necessário.

\section{APOIO}

Os autores agradecem à Associação de Agricultores e Irrigantes da Bahia pelo apoio logístico nos testes de campo e ao Conselho Nacional de Desenvolvimento Científico e Tecnológico pela concessão de bolsa de estudos à primeira autora.

\section{REFERÊNCIAS}

BONO, J. A. M.; MACEDO, M. C. M.; TORMENA, C. A.; NANNI, M. R.; GOMES, E. P.; MÜLLER, M. M. L. Infiltração de água no solo em um latossolo vermelho da região sudoeste dos cerrados com diferentes sistemas de uso e manejo. Revista Brasileira de Ciência do Solo, v. 36, n. 6, p.1845-1853, 2012.

COELHO, R. D.; MIRANDA, J. H. de; DUARTE, S. N. Infiltração da água no solo: parte I - infiltrômetro de anéis versus infiltrômetro de aspersores. Revista Brasileira de Engenharia Agrícola e Ambiental, v. 4, n. 2, p. 137-141, 2000.

LIMA FILHO, A. F.; COSTA, R. S. da. Construção de um equipamento automático para determinação da infiltração da água no solo. In: CONGRESSO BRASILEIRO DE ENGENHARIA AGRÍCOLA, 44., 2015, São Pedro. Anais eletrônicos... São Pedro-SP: SBEA, 2015. Disponível em: http://publicacoes.conbea.org.br/livros/baixar/62. Acesso em: 05 jul. 2017.

MOREIRA, L. F. F.; RIGHETTO, A. M.; MEDEIROS, V. $M$. de A. Infiltrômetro de carga constante na determinação das propriedades hidrológicas do solo. In: CONGRESSO DE INICIAÇÃO CIENTÍFICA DA UFRN, 12., 2002, Natal. Anais... Natal-RN: UFRN, 2002. v. 1. p. 45-52. Disponível em: <http://www.hidro.ufcg.edu.br/twiki/pub/Rehisa0/DocPu blicacoes/MicrosoftWord-

INFILTROMETRO_CARGA_CONSTANTE.pdf >. Acesso em: 23 jul. 2017.

PERROUX, K. M.; WHITE, I. Designs for disc permeameters. Soil Science Society of America Journal, v. 52, n. 5, p. 1205-1215, 1988.

SIMÕES, W. L.; FIGUEIRÊDO, V. B.; SILVA, E. L. da. Uso do cilindro infiltrômetro único em diferentes solos. Engenharia Agrícola, v. 25, n. 2, 2005. 